\title{
Isolated and simultaneous perceived barriers to physical activity counseling
}

\author{
Barreiras percebidas isoladas e simultâneas para o aconselhamento para atividade física
}

\author{
AUTHOR'S \\ João Miguel de Souza Neto ${ }^{1}$ (D) \\ Paulo Henrique Guerra² ${ }^{2}$ (D) \\ Emily Alves Rufino ${ }^{1}$ (D) \\ Filipe Ferreira da Costa ${ }^{1,3,4}$ (D) \\ 1 Grupo de Estudos e Pesquisas em Epidemiologia \\ da Atividade Física, João Pessoa, Paraíba, Brasil. \\ 2 Universidade Federal da Fronteira Sul, Chapecó, \\ Santa Catarina, Brasil. \\ 3 Programa Associado de Pós-Graduação em \\ Educação Física UPE/UFPB, João Pessoa, Paraíba, \\ Brasil. \\ 4 Programa de Pós-Graduação em Saúde Coletiva, \\ Universidade Federal da Paraíba, João Pessoa, \\ Paraiba, Brasil
}

\section{CORRESPONDING}

João Miguel de Souza Neto

miguel.edf@hotmail.com

Universidade Federal da Paraíba, Centro de

Ciência da Saúde, Departamento de Edu-

cação Física. Grupo de Estudos e Pesquisas em Epidemiologia da Atividade Física,

Prédio da Pós-graduação em Educação Física, Sala 20. Cidade Universitária, João Pessoa,

Paraíba, Brasil.

CEP: 58051-900.

\section{DOI}

10.12820/rbafs. $24 \mathrm{e} 0098$

\begin{abstract}
The aim of this study was to determine the prevalence of perceived barriers and their isolated and simultaneous association with the practice of counseling for physical activity by primary health care workers. This is a cross-sectional study with 591 health workers, who work in the Family Health Teams. Counseling for physical activity was defined as the accomplishment of such a practice for more than six months. The barriers investigated were lack of time, lack of knowledge, lack of professionals to guide, lack of available instructional material, lack of environmental resources and lack of financial resources of the user. Binary logistic regression was used to evaluate the possible relationships between perceived barriers and the practice of counseling for physical activity. Non-counselors reported a lack of time (68.8\%), knowledge (68.5\%) and orientation (63.2\%) compared to their peer counselors $(\mathrm{p} \leq 0.001)$. Professionals with three or more barriers were more likely not to advise (OR $=3.91 ; 95 \% \mathrm{CI}: 2.10-7.29)$ when compared to those who reported no concurrent barriers. These results indicate that the simultaneity of perceived barriers is negatively associated to the practice of counseling for physical activity of health workers.
\end{abstract}

Keywords: Health personnel; Counseling; Motor activity; Primary health care.

RESUMO

O objetivo deste estudo foi determinar a prevalência das barreiras percebidas e sua associação isolada e simultânea com a prática de aconselhamento para atividade física por profissionais da atençâo primária à saúde. Foi conduzido um estudo transversal com 591 profissionais da Estratégia de Saúde da Família. O aconselhamento para a atividade física foi definido como a realização de tal prática há mais de seis meses. As barreiras investigadas foram a falta de tempo, falta de conhecimento, falta de profissionais para orientar, falta de material instrucional disponivel, falta de recursos ambientais e falta de recurso financeiro do usuário. Utilizou-se a regressão logística binária para avaliar as associações entre barreiras percebidas e a prática de aconselhamento. Profissionais não aconselhadores relataram em maior proporção a falta de tempo (68,8\%), de conhecimento $(68,5 \%)$ e de orientação (63,2\%) comparados aos seus pares aconselhadores $(p \leq 0,001)$. Profissionais com três ou mais barreiras apresentaram maior chance de não aconselhar $(O R=3,91$; IC95\%: 2,10 - 7,29) quando comparados com aqueles que não relataram barreiras simultâneas. Os resultados sugerem que a simultaneidade de barreiras percebidas contribui negativamente na prática do aconselbamento para atividade física.

Palavras-chave: Pessoal de saúde; Aconselhamento preventivo; Atividade motora; Atenção primária à saúde.

\section{(cc) BY-NC-SA}

This work is licensed under the Creative Commons Attribution-NonCommercial-ShareAlike 4.0 International License.

\section{Introduction}

Several governmental strategies are gradually being implemented in Brazil to consolidate the promotion of physical activity in the context of the Unified Health System $(S U S)^{1}$. Considering that primary health care (PHC) is the front-line of health promotion and care of Brazilian people ${ }^{2}$, one of the main strategies used in promoting physical activity in this context is cou- nseling ${ }^{3}$, which can be understood as a general and structured orientation directed to motivate a user or patient of the SUS to initiate or continue physical activity practice, especially in the domains of leisure and transportation ${ }^{4}$.

Previous studies have shown beneficial effects of physical activity counseling ${ }^{5}$, as well as improvement in clinical and physical fitness indicators ${ }^{6-8}$. In considering 
its systemic development, this is also a low-cost strategy that can be performed by any well-trained health worker and in different contexts (e.g., routine health care, home visits, health promotion $)^{9}$. The Brazilian National Policy on Health Promotion indicates physical activity counseling as one of the priority themes ${ }^{10}$. However, it is observed that few SUS patients have received counseling aimed at performing physical activity to improve health ${ }^{11}$.

Some perceived barriers may explain the low adherence of health workers to physical activity counseling to health users ${ }^{11,12}$. These may be related to the training of professionals (either in initial training and/or continuing education), absence of support (lack of teaching materials, lack of referral options), sociocultural issues of users (poor living conditions, lack of success in changing patients' behavior), ${ }^{13}$ or the management of health services (lack of time due to excess demand, low priority for preventive actions) ${ }^{12,14}$.

However, it should be mentioned that the identification of almost all of these barriers occurred in international studies conducted in high-income countries where health systems and social structures are quite discrepant from the Brazilian reality. In addition, these studies only focused on describing and/or verifying isolated association of such barriers in health workers' counseling practices, thereby ignoring the cumulative or synergistic effect such barriers may have on worker practice. Thus, analyses involving the possible associations of simultaneous exposure to perceived barriers by Brazilian health professionals working in the SUS context may contribute to a better understanding of the factors that hinder the actions of promotion of physical activity in basic health units. Therefore, this study aimed to determine the prevalence of perceived barriers and their isolated and simultaneous associations with the lack of physical activity counseling by PHC workers.

\section{Methods}

A cross-sectional epidemiological study was conducted targeting health workers of the Family Health teams in the city of Joao Pessoa, Paraíba. The following parameters were adopted in the sample calculation: finite population size equal to 2,009 health workers (192 physicians, 204 nurses, 194 nursing assistants and 1419 community health agents); 50\% counseling prevalence for performing physical activity; acceptable maximum error of five percentage points; confidence level of $95 \%$; designing effect equal to $1.5 ; 30 \%$ increase for losses and refusals. This resulted in a sample size of 628 health workers (62 physicians, 63 nurses, 62 nursing assistants and 441 community agents).

Participants were selected using single-stage clusters, considering that each health team has at least one physician, one nurse, one nursing assistant and seven community health agents.

Forty-three out of 98 health units were randomly selected, considering stratification by health district (I, II, III, IV and V) and size of units (according to the number of family health teams): those with a (isolated) team; with two and three teams; and with four and five teams, maintaining representation by professional category. We included workers from the permanent and temporary staff of the Municipal Health Department who had been working for at least three months. Health workers who were inactive, on vacation or medical leave were excluded.

Data were collected by a previously trained research team between May and October 2017. All information was collected using the previously validated "Assessment Questionnaire for Counseling and Physical Activity Promotion by Health Workers" ${ }^{15}$. The instrument covered questions about the level of physical activity, knowledge, skills and attitudes related to the physical activity subject, sociodemographic data, initial and continuing training of workers, among others. Participants filled out the questionnaire at health facilities during team meetings, following instructions provided by the research team.

Physical activity counseling was assessed by asking the question "Considering physical activity counseling as a structured and general advice for physical activity practice in different domains (i.e. commuting and leisure), mark an option that better represents your behavior related to physical activity counseling". A six option scale based on the transtheoretical model ${ }^{12}$ was used as follow: precontemplation (i.e. I do not advise physical activity and I do not intend to begin); contemplation (i.e. I do not counsel physical activity, but I am starting think to do); preparation (i.e. Sometimes I do counsel physical activity, but not in a regular basis); action (i.e. I counsel physical activity, but I started to do it just recently); maintenance (i.e. I have been counseling for physical activity for at least 6 months); relapse (i.e. I used to advise physical activity, but I do not do anymore). Health workers who had not performed such practice for more than six months were classified as "non-counselors" (kappa $=0.92 ; 95 \% \mathrm{CI}: 0.87-0.97$ ). 
Barriers to physical activity counseling were identified through a multiple-choice question with six items: "lack of time due to job demand", "lack of knowledge about the subject", "lack of educational material (i.e. folder, booklets)", "lack of environmental resources (i.e. parks, streets)", "lack of specialized professional to teach how to do it" and "lack of financial resources of the user". The option "other" was given in a blank field and health workers could mark more than one option. Satisfactory reliability levels were found for this measure, with kappa values ranging from 0.56 to 0.83 .

Finally, independent variables included gender (male and female), age (categorized as: 20-29, 30-39, $40-49$ and $\geq 50$ years of age), educational level (high school, technical course, higher education, graduation), skin color (parda, black, white, yellow and indigenous), gross income based on minimum wage ( $S M$ - salário minimo [\$937,00]) (grouped in 1 to $2 \mathrm{SM}, 3$ to $4 \mathrm{SM}$ and $\geq 5 \mathrm{SM}$ ) and number of patients attended per day (classified as excessive [ $3^{\text {rd }}$ tertile] vs non-excessive $\left[1^{\text {st }} / 2^{\text {nd }}\right.$ tertiles $]$ ), cut-off points were: $30,20,60$ and 32 , respectively, for doctors, nurses, nursing technicians, and community health workers]. Reliability of sociodemographic variables was high with kappa values higher than 0.87 .

Descriptive analysis included frequency distribution for categorical variables, mean and standard deviation for continuous variables. Chi-square test for heterogeneity was used to compare the proportion of workers who reported barriers according to physical activity counseling status.

Binary logistic regression was used to evaluate the crude and adjusted association between the isolated and simultaneous barriers and physical activity counseling. A score was created based on the count of perceived barriers, ranging from none to six barriers. Potential confounders considered in this study were gender, age, educational level and number of patients attended per day. The independent variables were selected by the backward method, and all were considered in elaborating the multiple model (including isolated barriers), being introduced at the same level of analysis and kept in the model together with the confounding factors regardless of their respective levels of significance. Those with higher values for deviance, BIC and AIC were maintained, as well as those that showed changes of at least $10 \%$ in the ORs (Odds Ratios), regardless of the $\mathrm{p}$-value of the variable. In order to ascertain the quality of the models, variance inflation factor values (less than five were considered adequate) were used to avoid the possibility of multicollinearity. The Hosmer-Lemeshow test was used to evaluate the quality of fit of the model.

Interaction was tested to analyze if the association between the isolated and simultaneous barriers and the practice of physical activity counseling were different in relation to the professional category (undergraduate vs high school/technical level). However, this variable had no significant interaction with the other study variables $(p>0.05)$. The statistical analyses were performed in Stata 13.0, adopting a significance level of $5 \%$ for two-tailed tests.

This study was approved by the Human Research Ethics Committee of the Health Sciences Centre from the Federal University of Paraiba (Protocol number 0349/16. CAAE: 56780116.5.0000.5188).

\section{Results}

From the 667 health workers participating in the study, 18 refused to participate, 20 were not found on at least three visits from the data collection team and 38 were excluded because they did not meet the inclusion criteria. Thus, the final sample of this study was composed of 591 health workers (88.6\%). Calculations carried out a posteriori showed that this sample has a power of $80 \%$ ( $\beta=20 \%$ and $\alpha=5 \%)$ to detect odds ratios equal to or greater than 1.63 as significant with prevalence of outcome between $50.7 \%$ and $54.9 \%$ (among the exposed) and between $62.4 \%$ and $66.5 \%$ among the unexposed.

Table 1 shows that the majority of health workers were female $(n=459,78.6 \%)$, with a mean age of 43.2 years $( \pm 9.6)$, married $(\mathrm{n}=345,58.6 \%)$, non-white $(\mathrm{n}=$ $424,72.2 \%$ ), with monthly income of 1 to 2 minimum wages $(n=472,80.3 \%)$ and did not provide counseling for physical activity for at least six months $(n=314,53.6 \%)$.

A higher proportion of non-counselors reported lack of time (68.8\%), knowledge (68.5\%) and guidance by a specialized professional $(63.2 \%)$ as barriers ( $\mathrm{p}<0.05$ ) compared to their peers who do counsel for physical activity (Figure 1).

Table 2 presents the crude and adjusted analysis for the association between perceived barriers and not counseling for physical activity by health workers. After adjusting for all barriers and other variables, three barriers remained associated: lack of time $(\mathrm{OR}=2.08$; 95\%CI: 1.26 - 3.42), lack of knowledge $(\mathrm{OR}=2.39$; 95\%CI: 1.55 - 3.69) and lack of orientation of a specialized professional $(\mathrm{OR}=1.63$; 95\%CI: $1.09-2.46)$. 
Table 1 - Sociodemographic characteristics, professional demands and practice of physical activity counseling of health workers, stratified by profession category, Joao Pessoa, Northeast Brazil, 2017.

\begin{tabular}{|c|c|c|c|c|c|c|c|c|c|c|}
\hline \multirow{2}{*}{ Variables } & \multicolumn{2}{|c|}{ Physician } & \multicolumn{2}{|c|}{ Nurse } & \multicolumn{2}{|c|}{ Nurse assistant } & \multicolumn{2}{|c|}{$\mathrm{CHW}^{*}$} & \multicolumn{2}{|c|}{ All } \\
\hline & $\mathrm{n}$ & $\%$ & $\mathrm{n}$ & $\%$ & $\mathrm{n}$ & $\%$ & $\mathrm{n}$ & $\%$ & $\mathrm{n}$ & $\%$ \\
\hline \multicolumn{11}{|l|}{ Gender } \\
\hline Female & 29 & 61.7 & 65 & 97 & 53 & 100 & 311 & 74.8 & 459 & 78.6 \\
\hline Male & 18 & 38.3 & 2 & 3 & - & - & 105 & 25.2 & 125 & 21.4 \\
\hline \multicolumn{11}{|l|}{ Age (in years) } \\
\hline $20-29$ & 17 & 37.8 & 3 & 4.5 & 1 & 1.9 & 10 & 2.4 & 31 & 5.3 \\
\hline $30-39$ & 9 & 20 & 21 & 31.8 & 18 & 33.3 & 174 & 42 & 222 & 38.2 \\
\hline $40-49$ & 2 & 4.4 & 17 & 25.8 & 20 & 37 & 140 & 33.7 & 179 & 30.8 \\
\hline$\leq 50$ & 17 & 37.8 & 25 & 37.9 & 15 & 27.8 & 91 & 21.9 & 149 & 25.7 \\
\hline \multicolumn{11}{|l|}{ Education } \\
\hline Complete high school & - & - & - & - & - & - & 216 & 51.5 & 216 & 36.6 \\
\hline Technical course & - & - & - & - & 44 & 80 & 76 & 18.1 & 121 & 20.5 \\
\hline Higher education & 25 & 53.2 & 16 & 23.2 & 7 & 12.7 & 97 & 23.2 & 145 & 24.5 \\
\hline Graduation & 22 & 46.8 & 53 & 76.8 & 4 & 7.3 & 30 & 7.2 & 109 & 18.4 \\
\hline \multicolumn{11}{|l|}{ Gross income } \\
\hline 1 to 2 minimum wage & - & - & - & - & 55 & 100 & 416 & 100 & 472 & 80.3 \\
\hline 3 to 4 minimum wages & 6 & 12.8 & 65 & 94.2 & - & - & - & - & 71 & 12.1 \\
\hline$\leq 5$ minimum wages & 41 & 87.2 & 4 & 5.8 & - & - & - & - & 45 & 7.6 \\
\hline \multicolumn{11}{|l|}{ Skin color } \\
\hline Parda & 22 & 46.8 & 32 & 46.4 & 30 & 54.6 & 270 & 64.4 & 357 & 60.0 \\
\hline Black & - & - & 2 & 2.9 & 5 & 9.1 & 43 & 10.3 & 50 & 8.4 \\
\hline White & 23 & 49.0 & 30 & 43.4 & 18 & 32.7 & 91 & 21.7 & 162 & 27.5 \\
\hline Yellow & 1 & 2.1 & 4 & 5.8 & 1 & 1.8 & 8 & 1.9 & 14 & 2.4 \\
\hline Indigenous & 1 & 2.1 & 1 & 1.5 & 1 & 1.8 & 7 & 1.7 & 10 & 1.7 \\
\hline \multicolumn{11}{|l|}{ Number of patients attended per day } \\
\hline Excessive [3rd tertile] & 14 & 29.8 & 20 & 29 & 18 & 32.7 & 82 & 19.6 & 135 & 22.8 \\
\hline Non-excessive [1st/2nd tertiles] & 33 & 70.2 & 49 & 71 & 37 & 67.3 & 337 & 80.4 & 456 & 77.2 \\
\hline \multicolumn{11}{|l|}{ Physical activity counseling } \\
\hline Do counsel & 35 & 74.5 & 41 & 60.3 & 17 & 31.5 & 179 & 42.9 & 272 & 46.4 \\
\hline Do not counsel & 12 & 25.5 & 27 & 39.7 & 37 & 68.5 & 238 & 57.1 & 314 & 53.6 \\
\hline
\end{tabular}

*CHW = Community health work

There was a tendency to increase the odds of not counseling physical activity as the number of barriers reported by workers increased $(\mathrm{OR}=3.91 ; 95 \% \mathrm{CI}$ : 2.10 - 7.29) - Figure 2. The Hosmer-Lemeshow test result $\left(\chi^{2}=7.17 ; \mathrm{p}=0.34\right)$ showed that the model fit the data well. The values of the variance inflation factor - VIF did not identify multicollinearity $(\mathrm{VIF}<5$; Mean VIF = 1.41).

\section{Discussion}

The main perceived barriers to physical activity counseling among health workers were lack of time, know- ledge and specialized guidance on the subject. Health workers who reported a greater number of barriers were more likely not to undertake counseling for physical activity for more than six months.

A common obstacle to encompass physical activity into the daily routine of primary healthcare and associated with non-counseling is lack of time, which has consistently been cited both in quantitative ${ }^{11,16}$ and qualitative $^{17,18}$ studies. A systematic review pointed out lack of time during the health consultations, lack of knowledge and/or skill, followed by the absence of periodic training in physical activity counseling as 
Proportion of barriers to physical activity counseling

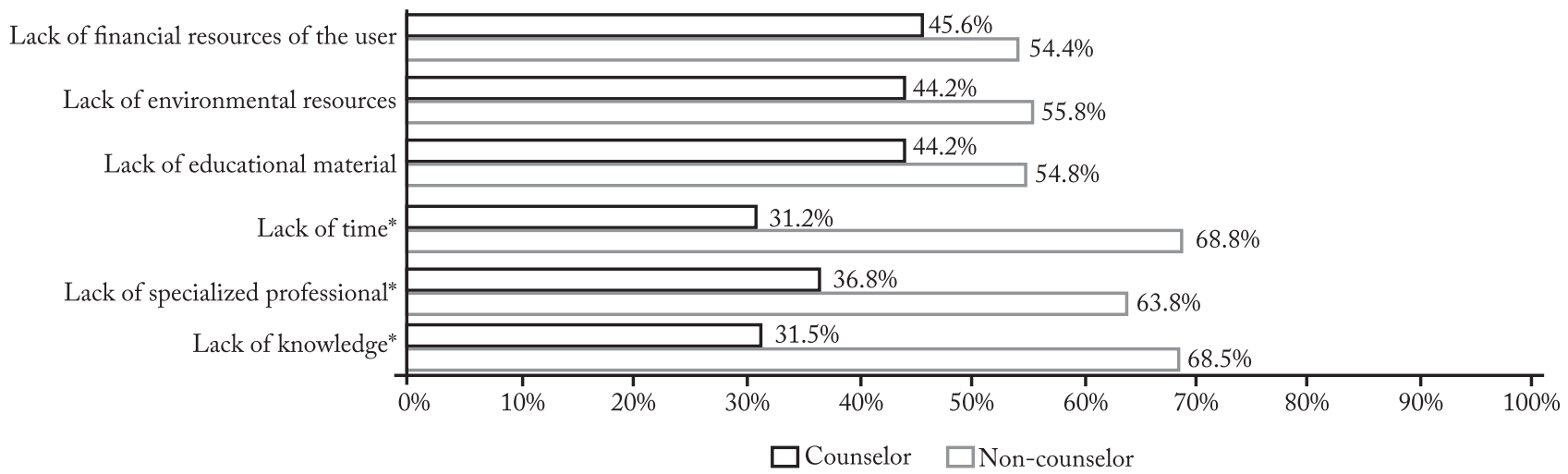

Figure 1 - Prevalence of perceived barriers to physical activity counseling among health workers from Joao Pessoa, Northeast Brazil, 2017. $* \mathrm{p}<0.05$ for the chi-square test.

Table 2 - Crude and adjusted analysis of the association between perceived barriers and non-performance of physical activity counseling among health workers from Joao Pessoa, Northeast Brazil, 2017.

\begin{tabular}{|c|c|c|}
\hline \multirow[b]{2}{*}{ Variables } & \multicolumn{2}{|c|}{ Do not counsel for physical activity } \\
\hline & $\begin{array}{l}\text { Crude OR } \\
(95 \% \mathrm{CI})\end{array}$ & $\begin{array}{l}\text { Adjusted OR* } \\
(95 \% \mathrm{CI})\end{array}$ \\
\hline \multicolumn{3}{|c|}{ Lack of time } \\
\hline No & 1 & 1 \\
\hline Yes & $2.13(1.34-3.40)$ & $2.08(1.26-3.42)$ \\
\hline \multicolumn{3}{|c|}{ Lack of knowledge } \\
\hline No & 1 & 1 \\
\hline Yes & $2.27(1.52-3.39)$ & $2.39(1.55-3.69)$ \\
\hline \multicolumn{3}{|c|}{$\begin{array}{l}\text { Lack of orientation from } \\
\text { specialized professional }\end{array}$} \\
\hline No & 1 & 1 \\
\hline Yes & $1.74(1.21-2.50)$ & $1.63(1.09-2.46)$ \\
\hline \multicolumn{3}{|c|}{ Lack of educational material } \\
\hline No & 1 & 1 \\
\hline Yes & $1.14(0.81-1.60)$ & $1.09(0.74-1.61)$ \\
\hline \multicolumn{3}{|c|}{ Lack of environmental resources } \\
\hline No & 1 & 1 \\
\hline Yes & $1.11(0.74-1.65)$ & $1.22(0.78-1.91)$ \\
\hline \multicolumn{3}{|c|}{ Lack of financial resources of the user } \\
\hline No & 1 & 1 \\
\hline Yes & $0.68(0.42-1.10)$ & $0.62(0.37-1.08)$ \\
\hline
\end{tabular}

*Ajusted for all perceived barriers plus gender, age, education and number of patients attended. $\mathrm{OR}=$ odds ratio $95 \% \mathrm{CI}=$ confidence interval

frequent barriers to performing physical activity counseling by health workers ${ }^{13}$. Patra et al. ${ }^{19}$ found physicians who attended up to 30 patients daily were five times more likely to perform physical activity counseling compared to their peers who had a greater number of daily consultations.

A telephone survey conducted in Brazil with physi-

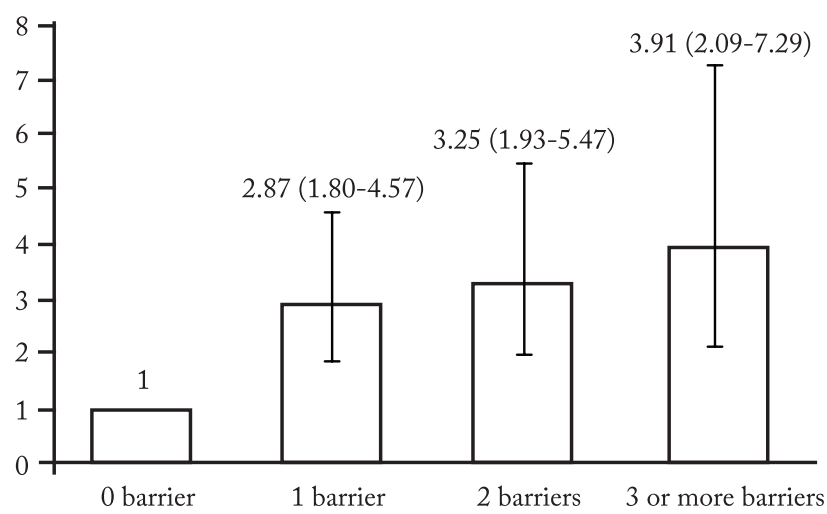

Figure 2- Simultaneity of perceived barriers and non-performance of physical activity counseling in health workers in Joao Pessoa, Northeast Brazil, 2017.

* $\mathrm{p}<0.001$ for linear trend

cians and nurses showed a linear relationship between the weekly number of patients attended and the workers' reports about lack of time as a barrier to counseling ${ }^{11}$. These findings point to the need to build and accommodate a work process in the $\mathrm{PHC}$ which will provide an organizational solution to this problem in order to ensure a better balance between promotion, prevention, treatment and rehabilitation actions. Although service organization is important, structural determinants can directly and negatively impact on the capacity of health workers to act on an educational perspective ${ }^{20}$.

Another commonly associated factor with non-counseling for physical activity is the lack of professional knowledge about how to do it. In fact, available evidence suggests that general recommendations as well as health education strategies to address physical activity is poorly embraced by initial training courses for physicians, nurses and other health workers ${ }^{4,21}$. On the other hand, curricula which systematize physical activity as a subject of physicians training seems to be effective for 
improving attitude, knowledge, skills and self-efficacy of the graduates to perform physical activity counseling ${ }^{21}$.

Training the health workforce seems to be critical for consolidating physical activity counseling as a health promotion strategy in PHC. It may contribute to the disruption of the still predominant biological, curative and physician-centered practices in PHC. On the other hand, it may help consolidate structuring principles and practices in health advocated by the $\mathrm{Na}-$ tional Primary Care Policy ${ }^{2}$. Ideally, health work training should encompass both initial (i.e. undergraduate courses) and continuing education (i.e. multiprofessional residence, in-service training).

Multiprofessional residence can contribute with different backgrounds, willing to move between different knowledge centers, articulate their specific knowledge in the organization of work, and allow both share actions and delegate activities to other health workers in the form of a collaborative practice. Therefore, strategies based on training PHC residents on physical activity counseling comprise an important step to disseminate this educational intervention to health users $^{22}$. In this same study, the authors reinforced the need for educational actions which are more specifically aimed at increasing the perception of self-efficacy and positive attitudes of residents, seeking to contribute to attenuate the perception of barriers and increase the probability of engagement in this practice ${ }^{22}$.

While curricular reforms and multiprofessional residency do not clearly cover the promotion and education for physical activity subjects in the Brazilian universities, an alternative and already available strategy to face this deficiency comprises the in-service training. The well-known Family Health Support Center, now called the Family Health and Primary Health Care Expanded Support Center $(N A S F-A B)$, comprises an multiprofessional team aimed at expanding the action scope of primary health care teams, providing specialized rearward training in health actions and increasing the effectiveness of healthcare in primary care $^{23}$. Through technical and pedagogical support to the teams, as well as the assistance dimension of support, health workers of several scientific areas can assist initiatives of health teams, and collaboratively build working processes that promotes health care integrality. Physical education comprises the list of possible professional categories on $N A S F-A B$, and therefore has the potential to lead actions focused on physical activity promotion and health education.
Perception of lack of environmental resources, instructional material and financial resources did not present an isolated association with physical activity counseling; however, it was cited by half the workers, and therefore also deserves attention when discussing actions to promote health in the community. These aspects contributed to the simultaneity analyses, which indicated that health workers who perceive a greater number of barriers have a greater chance of not performing physical activity counseling. Such a finding suggests that the perceived barriers to practice counseling for physical activity are prone to accumulate. This is possibly associated to other factors such as the development, implementation and effect of socio-organizational and sociopolitical innovation, resources and support, as well as characteristics of workers, users and the socioeconomic context ${ }^{24}$.

A closer connection between referral teams and $N A S F-A B$ workers can potentially relieve some of the barriers perceived by doctors, nurses and community health workers. With support from specialized professionals it is possible to face the shortage of instructional material (i.e. collective construction of folders and educational materials), knowledge and intervention models (i.e. discussion of methodological alternatives for intervention), time (i.e. optimization and rationalization of work processes) and even environmental resources (i.e. mapping of the territory and creation of physical activity networks ${ }^{23}$. In addition, the $N A S F-A B$ worker can form a link with the other health network equipment and services, such as the Health Academy Program (Programa Academia da Saúde - PAS), which was proposed as a key element for expanding and articulating actions to promote physical activity within the scope of PHC, aiming to promote health and quality of life for the population, based on the requalification and/or construction of buildings with infrastructure to physical activity practice, linking educational health actions that foster favorable conditions for health development and the empowerment of individuals and communities ${ }^{25}$.

Although the questionnaire used has an open field for including other barriers by the respondents, it is possible that many important and determinant aspects to perform counseling have not been contemplated. Care in constructing and validating the instrument contributed to the quality of the information, but the effects of suggesting barrier options are unknown. Also, we are unaware of the effect of data collection period on the counseling practices as well as time of 
health worker experience at the health unit. Therefore, qualitative studies may aid in the more comprehensive and in-depth understanding of the investigated phenomenon.

We can therefore conclude that health workers who perceive educational barriers, as well as those related to the structure and functioning of health services, are more unlikely to perform physical activity counseling. The scenario is even worse when increasing the number of perceived barriers. Thus, acting on the physical activity theme in the initial, continuous and in-service education of health workers seems to be fundamental to promote changes in professional practices and the organization of work itself in PHC, as well as to contemplate one of the priority guidelines in the context of Brazilian health promotion policies. Multiprofessional health teams that includes physical education professionals is, therefore, important to cover some of these needs.

\section{Conflict of interest}

The authors declare no conflicts of interest.

\section{Autor's contributions}

Souza Neto JM, participated in the article design, data collection and analysis, literature review and manuscript writing. Guerra $\mathrm{PH}$, contributed to the writing and critical revision of the manuscript. Rufino EA, participated in the collection and analysis of data and writing of the manuscript. Costa FF, participated in all stages of the study, including article design, data collection and analysis, and critical review of the manuscript.

\section{Acknowledgements}

The authors wish to thank all those people who directly or indirectly contributed to this project, especially professionals, managers and funding agency (CAPES scholarship).

\section{References}

1. Loch MR, Knuth AG, Silva ICM, Guerra PH. As práticas corporais/atividade física nos 30 anos do Sistema Único de Saúde. Cien Saude Colet. 2018;23(2):3469.

2. Brasil. Ministério da Saúde. Secretaria de Atenção à Saúde. Departamento de Atenção Básica. Política Nacional de Atenção Básica, Brasília: MS; 2012.

3. Grossman DC, Bibbins-Domingo K, Curry SJ, Barry MJ, Davidson KW, Doubeni CA, et al. Behavioral counseling to promote a healthful diet and physical activity for cardiovascular disease prevention in adults without cardiovascular risk factors: US Preventive Services Task Force recommendation statement. Jama. 2017;318(2):167-74.

4. Florindo AA, Andrade DR. Organizadores. Experiências de promoção da atividade física na estratégia de saúde da família. Florianópolis: Sociedade Brasileira de Atividade Física e Saúde; 2015.
5. Gomes MA, Duarte MFS. Efetividade de uma intervenção de atividade física em adultos atendidos pela estratégia saúde da família: Programa Ação e Saúde Floripa-BRASIL. Rev Bras Ativ Fis Saúde. 2008;13(1):44-56.

6. Jacobson DM, Strohecker L, Compton MT, Katz DL. Physical activity counseling in the adult primary care setting: position statement of the American College of Preventive Medicine. Am J Prev Med. 2005;29(2):158-62.

7. LeFevre ML. Behavioral counseling to promote a healthful diet and physical activity for cardiovascular disease prevention in adults with cardiovascular risk factors: U.S. Preventive Services Task Force Recommendation Statement. Ann Intern Med. 2014;16(1): 587-93.

8. National Institute for Health and Care Excellence (NICE) Physical activity: brief advice for adults in primary care. Nice: 2013.

9. Brasil. Ministério da Saúde. Política nacional de promoção da saúde (PNPS): revisão da Portaria MS/GM no 687, de 30 de março de 2006. Brasília: 2015.

10. Siqueira FV, Nahas MV, Facchini LA, Silveira DS, Piccini RX, Tomasi E, et al. Counseling for physical activity as a health education strategy. Cad Saude Publica. 2009; 2(5):203-13.

11. Florindo AA, Mielke GI, Gomes GAO, Ramos LR, Bracco MM, Parra DC, et al. Physical activity counseling in primary health care in Brazil: a national study on prevalence and associated factors. BMC Public Health. 2013;13(1):794.

12. Souza Neto JM, Florindo AA, Costa FF. Associated factors with physical activity counseling among Brazilian Family Health Strategy workers. Cien Saude Colet. No prelo 2019.

13. Hebert ET, Caughy MO, Shuval K. Primary care providers' perceptions of physical activity counselling in a clinical setting: a systematic review. Br J Sports Med. 2012; 4(6):625-31.

14. Tulloch H, Fortier M, Hogg W. Physical activity counseling in primary care: who has and who should be counseling? Patient Educ Couns. 2006;64(1-3):6-20.

15. Souza Neto JM. Prevalência e fatores associados à prática do aconselhamento para a atividade física em profissionais de saúde. [dissertação]. João Pessoa, Paraíba: Universidade Federal da Paraíba; 2018.

16. Douglas F, Torrance N, Van Teijlingen E, Meloni S, Kerr A. Primary care staff's views and experiences related to routinely advising patients about physical activity. A questionnaire survey. BMC Public Health. 2006;6(1):138.

17. Bize R, Cornuz J, Martin B. Opinions and attitudes of a sample of Swiss physicians about physical activity promotion in a primary care setting. Schweiz $Z$ Med Traumatol. 2007;55(3):97-100.

18. Graham R, Dugdill L, Cable N. Health professionals' perspectives in exercise referral: implications for the referral process. Ergonomics. 2005;48(11-14):1411-22.

19. Petrella RJ, Lattanzio CN, Overend TJ. Physical Activity Counseling and Prescription Among Canadian Primary Care Physicians. Arch Intern Med. 2007;16(7):1774-81.

20. Morosini MVGC, Fonseca AF, Lima LDd. Política Nacional de Atenção Básica 2017: retrocessos e riscos para o Sistema Único de Saúde. Rev Saúde em Debate. 2018;42(1):11-24.

21. Dacey ML, Kennedy MA, Polak R, Phillips EM. Physical activity counseling in medical school education: a systematic review. Med Educ Online. 2014;19(1):24325.

22. Wattanapisit A, Tuangratananon T, Thanamee S. Physical activity counseling in primary care and family medicine residency training: a systematic review. BMC Med Educ. 2018;18(1):159. 
23. Brasil. Ministério da Saúde. Secretaria de Atenção à Saúde. Departamento de Atenção Básica. Diretrizes do NASF: Núcleo de Apoio a Saúde da Família. Brasília: 2010.

24. Huijg JM, Gebhardt WA, Verheijden MW, Van der Zouwe N, Vries J.D, Middelkoop BJC, Crone M.R . Factors influencing primary health care professionals' physical activity promotion behaviors: a systematic review. Int J Behav Med. 2014;22(1):32-50.
25. Brasil. Ministério da Saúde (MS). Portaria no 719, de 7 de abril de 2011. Institui o Programa Academia da Saúde no âmbito do Sistema Único de Saúde. Diário Oficial da União 2011; abr 8.

Receibed: $15 / 09 / 2019$

Approved: $31 / 03 / 2020$

\section{Quote this article as:}

Souza Neto JM, Guerra PH, Rufino EA, Costa FF. Isolated and simultaneous perceived barriers to physical activity counseling. Rev Bras Ativ Fis Saúde. 2019;24:e0098. DOI: 10.12820/rbafs.24e0098 